\title{
Influência das Microestruturas Resultantes no Desgaste Abrasivo e por Deslizamento de um Aço Estrutural ASTM A242 Soldado pelo Processo MAG
}

\author{
Daniela Fátima Giarollo ${ }^{1}$, Cintia Cristiane Petry Mazzaferro ${ }^{1}$ \\ 1 Universidade Federal do Rio Grande do Sul, Programa de Pós-graduação em Engenharia Mecânica, Laboratório de Soldagem \\ \& Técnicas Conexas, Porto Alegre, RS, Brasil.
}

Recebido: 25 Out., 2017

Aceito: 30 Maio, 2018

E-mail: danielagiarollo@hotmail.com (DFG)
Resumo: O objetivo do presente trabalho foi verificar o efeito das alterações microestruturais resultantes da soldagem na resistência ao desgaste de uma junta de aço estrutural ASTM A242, comparando com o comportamento do metal base. Utilizou-se o processo de soldagem MAG e arame AWS ER70S-6. A soldagem foi automatizada, na posição plana, utilizando chanfro em $\vee$ e realizada por uma fonte eletrônica em $C C+$. A região desgastada e os mecanismos foram caracterizados utilizando microscopia eletrônica de varredura, microscopia ótica e interferometria a laser. A resistência ao desgaste foi analisada por diferentes métodos: ensaio de desgaste Roda de Borracha, definido pela norma ASTM G65-16, e ensaio de microdesgaste por deslizamento linear recíproco, similar ao descrito pela norma ASTM G133-16. O ensaio de desgaste roda de borracha representou um comportamento geral da junta soldada, uma vez que a área de abrangência do ensaio é delimitada pela largura da roda de borracha. O resultado do ensaio mostrou que a junta soldada (metal de solda e parte da região da zona afetada pelo calor de grãos grosseiros (ZAC-GG)) apresentou melhor resistência ao desgaste do que o metal base. O ensaio de microdesgaste por deslizamento foi utilizado com o objetivo de analisar cada região da junta soldada, separadamente. Neste sentido, ensaios foram realizados no metal base, no metal de solda e na ZAC-GG, uma vez que esta região foi abrangida pelo ensaio roda de borracha. Neste ensaio, observou-se que a ZAC-GG apresentou maior resistência ao desgaste do que o metal de solda, e o metal base exibiu a menor resistência ao desgaste. Os resultados indicaram que a deformação plástica exibida pela microestrutura do metal base contribuiu para o maior desgaste, em ambos ensaios.

Palavras-chave: Soldagem; Desgaste abrasivo; Microdesgaste por deslizamento; Aço estrutural.

\section{Influence of Resulting Microstructures on Abrasive and Sliding Wear of a Structural ASTM A242 Steel Welded by GMAW}

\begin{abstract}
The aim of the present work was to verify the effect of microstructures on the wear resistance of an ASTM A242 structural steel welded joint, comparing it with the behavior of the base metal. The joints were produced using the GMAW process and AWS ER70S-6 wire electrode. The welding was automated, in flat position, using $\mathrm{V}$-groove and with an eletronic power source operating in CC+. Microstructural features of welded joints and worn surfaces as well as wear mechanisms were characterized using scanning electron microscopy, optical microscopy and laser interferometry. The wear resistance was analyzed by different wear tests: Dry Sand/Rubber Wheel Tests, defined by ASTM G65-16 and Linearly Reciprocating Ball-on-Flat Sliding Microwear, similar to that described by ASTM G133-16. The Rubber Wheel wear test indicated a general behavior of the weld joint, since the test range is limited by the width of the rubber wheel. In this test weld joint (weld metal and part of the coarse grain heat affected zone (CGHAZ)) showed better wear resistance than the base metal. The sliding microwear was used to analyze weld regions separately. In this sense, tests were performed on the base metal, weld metal and CGHAZ, since this region was covered by the Rubber Wheel wear test. Results showed a higher wear resistance in CGHAZ than in weld metal, and the lower wear resistance was observed in the base metal. This could be attributed to the higher plastic deformation in base metal.
\end{abstract}

Key-words: Welding; Abrasive wear; Sliding wear; Structural steel.

\section{Introdução}

O aço ASTM A242, também conhecido como aço resistente à corrosão atmosférica, é um aço com um teor de carbono inferior a 0,2\% em massa, ao qual, principalmente, $\mathrm{Cu}, \mathrm{Cr}, \mathrm{Ni}$, Si e Mn são adicionados como elementos de liga [1]. Durante a exposição ao
Este é um artigo publicado em acesso aberto (Open Access)
sob a licença (reative Commons Attribution Non-Commercial, que permite uso, distribuição e reprodução em qualquer meio, sem restrições des de que sem fins comerciais e que 0 trabalho original seja corretamente citado. 
ambiente, uma camada adesiva, compacta e protetora de produtos de corrosão, conhecida como pátina, cresce sobre a superfície, retardando a corrosão adicional. A pátina não só oferece maior resistência à corrosão, mas também é responsável por sua aparência atraente. As principais aplicações deste aço incluem estruturas civis, pontes, esculturas ornamentais, fachadas e coberturas, instalações rodoviárias e estruturas para transporte ferroviário [2]. No Brasil este aço vem sendo utilizado, entre outros, na fabricação de vagões para transporte de minério. Nesta aplicação, tanto a corrosão quanto o desgaste são passíveis de ocorrerem, interferindo na integridade destes sistemas.

$\mathrm{Na}$ indústria da mineração, Holmberg et al. [3] estimaram que são gastos aproximadamente 210 bilhões de Euros ao ano em problemas causados pelas perdas por atrito e desgaste em todo o mundo. Deste total, cerca de $27 \%$ são destinados para produção e substituição de peças e equipamentos devido a falhas provocadas pelo desgaste.

Muitos dos componentes ou estruturas submetidos a processos de desgaste são soldados durante a sua produção. Os processos de soldagem submetem os metais a ciclos térmicos e, como resultado, provocam alterações microestruturais, que afetam as propriedades localmente. Uma junta soldada compreende basicamente o metal base $(\mathrm{MB})$, a zona afetada pelo calor (ZAC) e o metal de solda (MS); a ZAC é a região na qual a temperatura atingida não é alta o suficiente para causar a fusão do material, mas sim para causar mudanças significativas na microestrutura e propriedades [4]. Em aços ao carbono e baixa liga a ZAC é comumente dividida em quatro sub-regiões que exibem diferentes microestruturas. Essas sub-regiões são conhecidas como região de crescimento dos grãos, também conhecida como região de grãos grosseiros; região de refino dos grãos; região intercrítica; e região subcrítica, na ordem de localização do metal de solda para o metal base [5].

Existem vários trabalhos disponíveis na literatura abordando o efeito da microestrutura gerada pelos processos de soldagem na resistência ao desgaste. No entanto, muitos destes referem-se a revestimentos aplicados por processos de soldagem [6-9], e não ao efeito do cordão de solda utilizado para a união de componentes.

Dentre os trabalhos que analisam o efeito da soldagem na resistência ao desgaste de juntas soldadas, Rojacz et al. [10] analisaram o efeito da microestrutura obtida em soldas de reparo através do processo de soldagem MAG em diferentes aços estruturais quanto às suas resistências à abrasão em altas temperaturas, tendo também realizado testes de dureza a quente. Os resultados indicaram uma forte dependência da microestrutura e da dureza, originadas de diferentes parâmetros de soldagem, na resistência ao desgaste. Neste estudo, menores resistências ao desgaste foram observadas em microestruturas contendo ripas de martensita mais grosseiras ou que continham maior quantidade de ferrita. Krishnan et al. [11] realizaram um estudo para avaliar o desgaste nas diferentes regiões de juntas soldadas pelo processo MAG, inclusive nas sub-regiões da ZAC, em um aço carbono-manganês. Neste trabalho, foi utilizado um equipamento do tipo pino sobre disco, os pinos foram produzidos a partir de material retirado das seções transversais ao metal de solda, e os discos confeccionados em aço. Os autores realizaram ensaios de desgaste contínuos, iniciando no metal base, passando pelas microestruturas nas sub-regiões da ZAC e finalizando no metal de solda. Também foram realizados testes de curta duração, para que cada ensaio permanecesse confinado apenas à microestrutura de interesse. Os autores observaram diferenças nas taxas de desgaste e na força de atrito nas sub-regiões da junta soldada. No entanto, o comportamento de desgaste das diferentes regiões da ZAC foi distinto quando os testes de desgaste foram realizados continuamente a partir do metal base ou quando em regiões isoladas da junta soldada, o que foi atribuído ao efeito variável do endurecimento do trabalho e da estabilidade térmica microestrutural: a maior resistência foi observada no metal base, o mesmo exibia microestrutura composta por ferrita e perlita na forma de bandas. Pontel [12], comparou o desgaste abrasivo Roda de Borracha, em juntas soldadas pelo processo MAG utilizando como metal base um aço de alta resistência mecânica, com matriz martensítica. Foram empregados dois metais de adição com composição química e propriedades mecânicas diferentes. A maior resistência ao desgaste foi observada para o MB, seguida pelo MS de maior dureza.

O objetivo do presente trabalho foi verificar a influência das microestruturas resultantes do processo de soldagem MAG na resistência ao desgaste de uma junta soldada de um aço estrutural ASTM A242, aplicado em equipamentos de transporte de minério, comparando-a ao comportamento do metal base. Para isso foram utilizados dois tipos de ensaio de desgaste: o ensaio de desgaste abrasivo Roda de Borracha, que representou um comportamento geral da junta soldada, e o ensaio de microdesgaste por deslizamento linear recíproco, onde foi possível avaliar regiões da junta soldada separadamente. 


\section{Materiais e Métodos}

O material utilizado neste estudo, fornecido pela empresa ArcelorMittal S.A, foi o aço ASTM A242 laminado a quente, com espessura de $4,75 \mathrm{~mm}$. Sua composição química é apresentada na Tabela 1 . A microestrutura era composta por ferrita (fase clara) e perlita (fase escura), Figura 1. O material apresentou dureza de 190,3 $\pm 5,9 \mathrm{HV}$ na direção longitudinal, 157,6 $\pm 3,5$ HV na direção transversal e 168,0 $\pm 3,2$ HV na direção normal, medidas com um microdurômetro Insize, utilizando uma carga de $300 \mathrm{~g}$ e tempo de $10 \mathrm{~s}$.

Tabela 1. Composição química [\% em massa] do metal base ASTM A242 e do metal de adição AWS ER70S-6.

\begin{tabular}{cccccccccc}
\hline & \multicolumn{1}{c}{ C } & \multicolumn{1}{c}{ Si } & Mn & Cu & Ni & Cr & Al & P & Fe \\
ASTM A242 & 0,082 & 0,416 & 0,617 & 0,24 & 0,119 & 0,033 & 0,04 & $<0,01$ & Bal. \\
AWS ER70S-6 [13] & 0,10 & 0,80 & 1,40 & - & - & - & - & - & Bal. \\
\hline
\end{tabular}

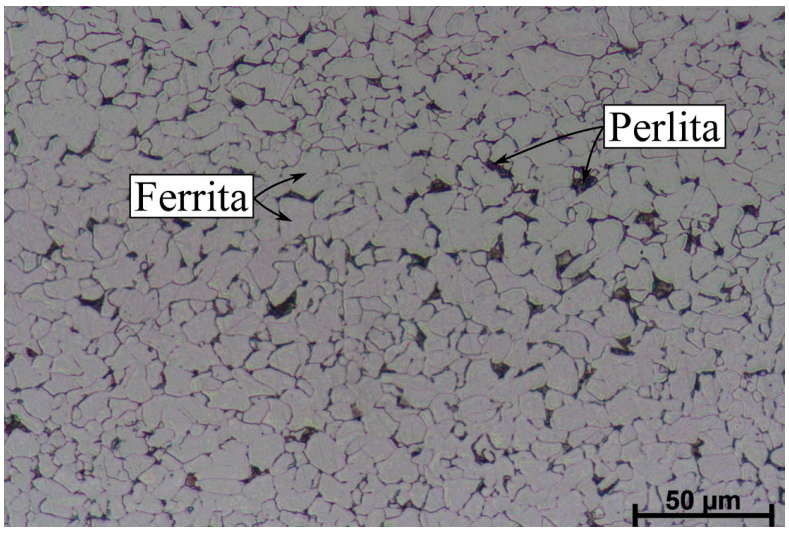

Figura 1. Microestrutura do metal base observada em microscópio ótico (ataque Nital 10\%): os grãos claros são ferrita e as regiões escuras, perlita.

\subsection{Processo de soldagem}

As chapas utilizadas no processo de soldagem possuíam as dimensões de $200 \times 100 \mathrm{~mm}$. Foi utilizada uma junta de topo com chanfro do tipo $V$, com a geometria mostrada na Tabela 2, a direção de soldagem foi longitudinal à laminação, na dimensão de $200 \mathrm{~mm}$.

Tabela 2. Parâmetros de Soldagem.

\begin{tabular}{|c|c|c|}
\hline Geometria da junta & \multicolumn{2}{|l|}{ Parâmetros de Soldagem } \\
\hline & Vazão do gás de proteção & $15 \mathrm{l} / \mathrm{min}$ \\
\hline & Velocidade de alimentação do arame & $5,2 \mathrm{~m} / \mathrm{min}$ \\
\hline & Velocidade de soldagem & $4 \mathrm{~mm} / \mathrm{s}$ \\
\hline & Tensão & $22,6 \mathrm{~V}$ \\
\hline & Corrente & 199,4 A \\
\hline $1,2 \mathrm{~m}$ & Distância do bico de contato à peça & $15 \mathrm{~mm}$ \\
\hline & Energia* & $901,3 \mathrm{~J} / \mathrm{mm}$ \\
\hline
\end{tabular}

*Considerando a eficiência do arco elétrico no processo MAG de 80\% [14].

O processo de soldagem utilizado foi o processo MAG convencional com fonte ajustada para trabalhar no modo tensão constante e polaridade CC+ (Corrente Contínua e Eletrodo Positivo). Utilizou-se um sistema robotizado, composto pela fonte TransPuls Synergic 4000R da marca Fronius e um robô MA1400 da Yaskawa Motoman Robotics, os valores instantâneos de corrente e tensão foram coletados pelo Sistema de Aquisição 
Portátil SAP 4.01 (IMC Soldagem). O gás de proteção utilizado foi o C25 (75\% de argônio e $25 \%$ de $\mathrm{CO}_{2}$ ) e o metal de adição foi o AWS ER70S-6, com 1,2 mm de diâmetro, cuja composição química está apresentada na Tabela 1. Todos os parâmetros utilizados no processo de soldagem são apresentados na Tabela 2.

\subsection{Ensaio de desgaste abrasivo roda de borracha}

Estes ensaios foram realizados utilizando-se um abrasômetro do tipo Roda de Borracha, construído segundo a norma ASTM G65-16 [15], representado na Figura 2, este sistema é formado por um disco revestido por um anel de borracha, que rotaciona com uma velocidade constante, sendo atritado contra a superfície da amostra, entre essas duas superfícies um fluxo abrasivo é alimentado com velocidade constante. Para este ensaio foram confeccionadas amostras retangulares de $76 \times 25 \mathrm{~mm}$, cortadas com o auxílio de uma cortadora metalográfica, fresadas para a obtenção de superfícies planas e paralelas. A superfície da realização do ensaio foi lixada com lixas de até 600 mesh. Nas amostras soldadas, o cordão de solda foi posicionado longitudinal ao maior comprimento da amostra e centralizado, a direção de soldagem coincidiu com o sentido de deslocamento da roda. Neste ensaio não foi possível separar as diferentes regiões da junta soldada, pois a espessura da trilha é limitada a espessura da roda, ou seja, $12,7 \mathrm{~mm}$.

(a)

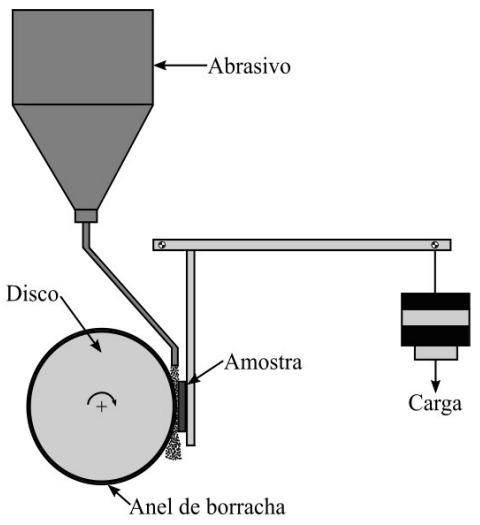

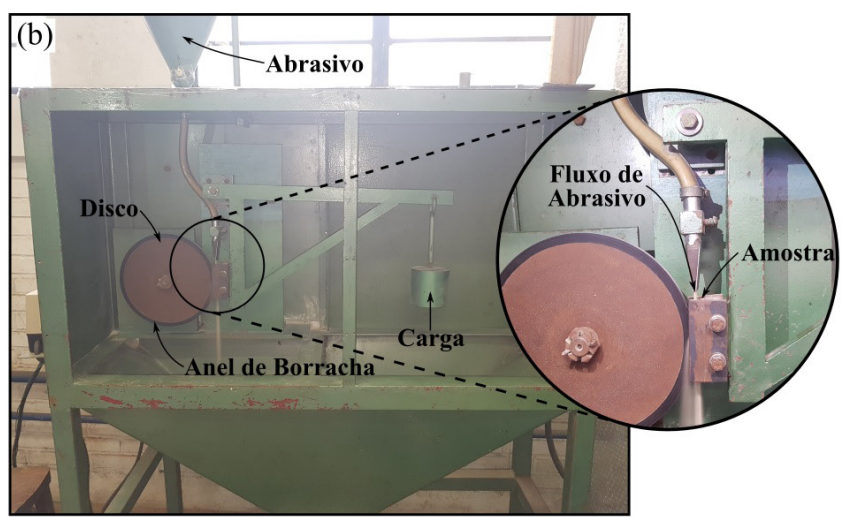

Figura 2. (a) Representação esquemática do equipamento Roda de Borracha. Adaptado de ASTM G65 [15]; e (b) Imagem do equipamento utilizado nos ensaios.

Na Tabela 3 são apresentados os parâmetros utilizados neste ensaio. Todos os experimentos foram realizados a temperatura ambiente. Neste trabalho, o abrasivo utilizado foi areia comumente empregada na construção civil, para tanto a mesma foi secada e classificada granulometricamente. Após, as partículas foram digitalizadas utilizando um microscópio ótico Zeiss Axio Lab.A1 e através da sua projeção 2D foi determinado o fator de arredondamento $\mathrm{K}_{\mathrm{R}^{\prime}}$, de acordo com a Equação 1 [16]:

$$
K_{R}=\frac{p^{2}}{4 \pi A}
$$

onde $\mathrm{p}$ é o perímetro e $\mathrm{A}$ a área da partícula.

Tabela 3. Parâmetros utilizados no ensaio Roda de Borracha.

\begin{tabular}{lc}
\hline \multicolumn{1}{c}{ Tipo de Borracha } & Neoprene \\
Dureza da Borracha & 74 Shore (A) \\
Diâmetro Inicial da Roda & $223,7 \mathrm{~mm}$ \\
Carga & $130 \mathrm{~N}$ \\
Rotação do disco & $216,4 \mathrm{rot} / \mathrm{min}$ \\
Tamanho do Abrasivo & $150-300 \mu \mathrm{m}$ \\
Fluxo de Abrasivo & $313 \mathrm{~g} / \mathrm{min}$ \\
Tempo de Ensaio & $10 \mathrm{~min}$ \\
\hline
\end{tabular}


Os abrasivos apresentaram $K_{R}=1,28$, o que significa que os mesmos possuem uma forma essencialmente arredondada. Na Figura 3 é apresentada uma imagem destes abrasivos.

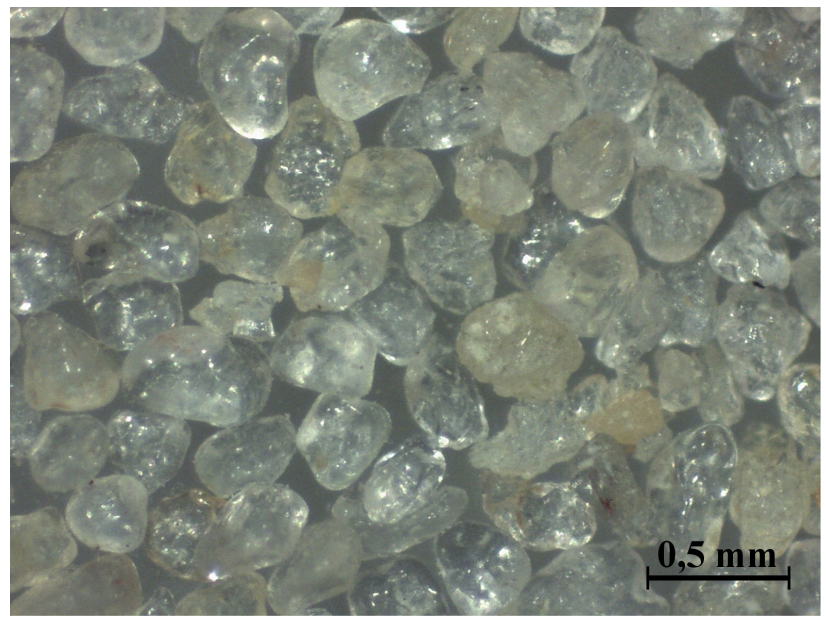

Figura 3. Abrasivos utilizados nos ensaios Roda de Borracha.

Segundo a norma ASTM G65-16 [15], o volume desgastado $P_{v^{\prime}}$ conforme a Equação 2, foi calculado através da densidade do material $\rho$ e da perda de massa $m$ registrada, para isto, antes e após cada ensaio as amostras eram limpas com acetona e suas massas determinadas em uma microbalança SHIMADZU AY220, com uma resolução de $10^{-4} \mathrm{~g}$.

$$
P_{v}\left(\mathrm{~mm}^{3}\right)=\frac{m(\mathrm{~g})}{\rho\left(\mathrm{g} / \mathrm{cm}^{3}\right)} \times 1000
$$

Como a roda de borracha também sofre abrasão, conforme ela diminui seu diâmetro, a abrasão desenvolvida em cada amostra é reduzida, a perda real de volume produzida por esta roda deve ser então ajustada. A perda de volume ajustada $P_{v a^{\prime}}$ mostrada na Equação 3, leva isto em consideração e indica a taxa de abrasão real que seria produzida por uma roda de 228,6 mm de diâmetro [15].

$$
P_{v a}\left(\mathrm{~mm}^{3}\right)=P_{v} \cdot \frac{228,6(\mathrm{~mm})}{d_{f}}
$$

onde $d_{f}$ é o diâmetro da roda após o uso.

A taxa de desgaste específico $k$ foi calculada de acordo com a Equação de Archard, Equação 4 [17]:

$$
k\left(\mathrm{~mm}^{3} / \mathrm{Nm}\right)=\frac{P_{v a}}{N \cdot s}
$$

onde $N$ é a carga normal aplicada, em $\mathrm{N}$ e $s$ a distância percorrida em $\mathrm{m}$.

\subsection{Ensaio de microdesgaste por deslizamento}

Os ensaios de microdesgaste por deslizamento linear recíproco foram realizados utilizando um equipamento do tipo esfera sobre chapa, similar ao descrito pela norma ASTM G133 [18], fabricado pela empresa TTP - Indústria Mecânica Ltda, ilustrado na Figura 4. Neste sistema, o movimento linear é realizado pela mesa onde a amostra plana é fixada e a carga é aplicada sobre a esfera, que possuía 4,76 mm de diâmetro. Para a realização dos ensaios, inicialmente as peças foram fresadas, removendo o reforço do cordão de solda, após lixadas, polidas com alumina $0,05 \mu \mathrm{m}$ e atacadas utilizando Nital 10\%, possibilitando a visualização das diferentes regiões do cordão de solda e facilitando o posicionamento da amostra para a realização dos ensaios. Pelo fato da região de ensaio ser pequena, com este ensaio foi possível avaliar diferentes regiões do cordão de solda separadamente. Neste sentido, optou-se 
por realizar ensaios no MB, no MS e na ZAC-GG, uma vez que o ensaio de desgaste roda de borracha também abrangeu parte destas regiões da ZAC. Para cada região, foram realizadas três repetições, todas longitudinais ao cordão de solda, e sem adição de lubrificante, a seco. Após cada ensaio, a esfera foi rotacionada ou substituída, obtendo assim uma nova área para o contato entre a esfera e a amostra. Os parâmetros utilizados nos ensaios estão descritos na Tabela 4.

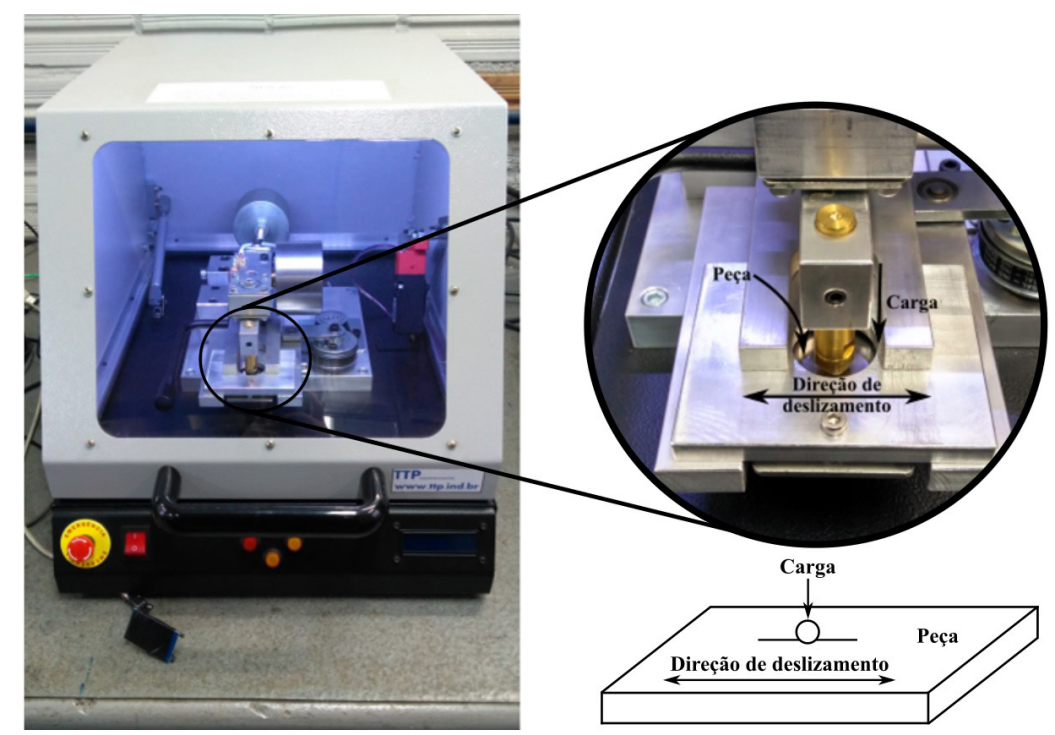

Figura 4. Máquina de ensaios de microdesgaste por deslizamento.

Tabela 4. Parâmetros utilizados nos ensaios de microdesgaste por deslizamento.

\begin{tabular}{lc}
\hline \multicolumn{1}{c}{ Frequência } & $\mathbf{1 ~ H z}$ \\
Força normal aplicada & $10 \mathrm{~N}$ \\
Tempo de ensaio & $2 \mathrm{~h}$ \\
Tamanho da trilha & $2 \mathrm{~mm}$ \\
Material da esfera & Alumina $\left(\mathrm{Al}_{2} \mathrm{O}_{3}\right)$ \\
Diâmetro da esfera & $4,762 \mathrm{~mm}$ \\
\hline
\end{tabular}

Para a medição do coeficiente de atrito, o equipamento de desgaste utiliza uma célula de carga do tipo viga fina com extensômetros montados na configuração ponte inteira, na qual todos são fixados na mesma posição e em lados opostos da viga, configuração esta que permite compensação do efeito térmico. A partir da coleta de dados, um software de aquisição e controle faz a leitura e os encaminha a um computador onde o coeficiente de atrito é calculo através da razão entre a força de atrito e a força normal aplicada.

As curvas do coeficiente de atrito cinético apresentam dois períodos. No período inicial ocorre o assentamento da esfera sobre a amostra e a ruptura da camada de óxidos superficiais existentes na amostra [19]. Em um segundo período, com a diminuição desta camada, começa a ocorrer o contato direto entre asperezas, neste período o coeficiente de atrito entra em regime permanente. Neste trabalho a média do coeficiente de atrito foi calculada durante o regime permanente (aproximadamente 15 minutos após a inicialização do ensaio).

Dependendo do par tribológico utilizado, o desgaste pode ocorrer somente na esfera, quando o material da amostra plana é muito mais resistente que o material da esfera, somente na amostra plana, quando o material da esfera é muito mais resistente, ou também o desgaste pode ser mensurável tanto na esfera quanto na amostra [18]. Neste estudo os dois corpos apresentaram desgaste, sendo necessária a medição em ambos. 
Para a medição do desgaste na esfera, fotos das marcas deixadas na esfera foram feitas com o auxilio de um microscópio ótico utilizando uma ampliação conhecida, Figura 5a, e posteriormente estas imagens foram analisadas em um programa de edição de imagens para medição da área da marca. Como a marca deixada era próxima à circular, esta área foi aproximada para um círculo de mesma área, Figura 5b. Para cada ensaio foi realizada uma média de 5 medições da área e esse valor utilizado para calcular o diâmetro efetivo da marca $(D)$. O volume desgastado na esfera $\left(V_{e}\right)$, Figura $5 c$, para cada marca de diâmetro efetivo $D$ é encontrado a partir da relação mostrada nas Equações 5 e 6 [18]:

$$
\begin{aligned}
& V_{e}=(\pi h / 6)\left[3 D^{2} / 4+h^{2}\right] \\
& h=R-\left[R^{2}-\left(D^{2} / 4\right)\right]^{1 / 2}
\end{aligned}
$$

onde $h$ é a altura do material removido e $R$ é o raio inicial da esfera, ambos em $\mathrm{mm}$.
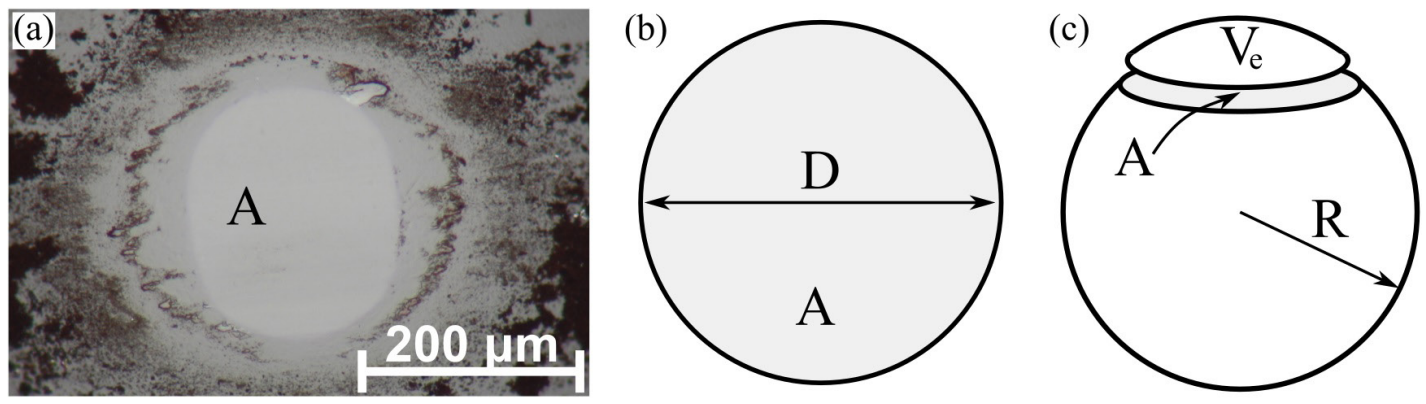

Figura 5. (a) Imagens da esfera desgastada; (b) Aproximação da área de desgaste na esfera por um círculo de mesma área; (c) Cálculo do volume desgastado na esfera.

Para o cálculo de volume de desgaste na trilha, perfis topográficos foram obtidos com a utilização de um Interferômetro Bruker - Contour GT, Figura 6a. Neste perfil, uma linha reta foi traçada entre as áreas não utilizadas no desgaste em ambos os lados da trilha, servindo como linha de referência, e a área da seção transversal da trilha $\left(A_{t}\right)$, abaixo dessa linha de referência, era usada para calcular o volume desgastado. Em cada trilha foram criadas 10 linhas transversais à trilha e igualmente espaçadas, obtendo perfis transversais conforme o exemplo da Figura 6b. As extremidades da trilha, onde ocorrem erros geométricos associados aos pontos de inversão de direção do movimento, foram negligenciadas. O volume de desgaste da amostra plana é calculado a partir do comprimento da trilha $L$ e da média da área das seções transversais da trilha, $A_{t}$, Equação 7 [18].

$$
V_{t}=A_{t} \times L
$$
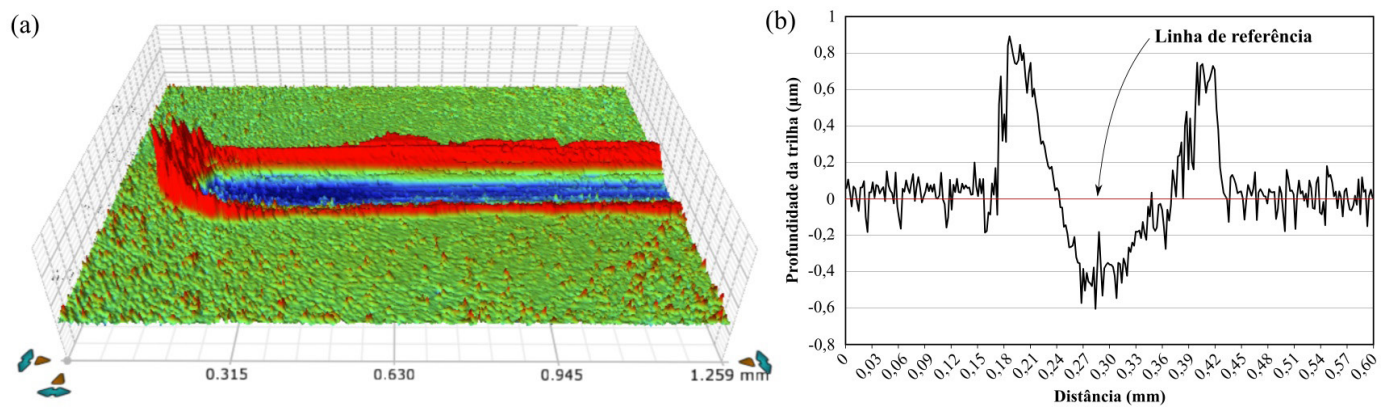

Figura 6. (a) Perfil topográfico gerado da superfície de meia trilha; (b) Gráfico 2D de uma linha transversal à trilha. 


\subsection{Caracterização da junta soldada e das superfícies desgastadas}

O perfil de microdureza Vickers foi produzido em uma seção transversal do cordão de solda a uma distância de $1 \mathrm{~mm}$ da superfície das chapas, com uma distância entre indentações de $0,5 \mathrm{~mm}$, empregando um microdurômetro Insize, com uma carga de $300 \mathrm{~g}$ e tempo de permanência da carga de $10 \mathrm{~s}$.

Para a análise da superfície desgastada e possível detecção dos mecanismos de desgaste foi utilizado um microscópio eletrônico de varredura (MEV) JEOL 6060. As microestruturas superficiais e subsuperficiais do ensaio de desgaste roda de borracha foram observadas em um microscópio ótico Zeiss Axio Lab.A1. Para esta observação as amostras foram cortadas transversalmente à direção de desgaste, e foram produzidas superfícies metalográficas polidas orientadas cerca de $20^{\circ}$ da superfície desgastada. Este método permitiu uma observação ampliada da superfície desgastada e da microestrutura da sub-superfície.

\section{Resultados e Discussão}

A Figura 7 apresenta imagens da superfície e da raiz do cordão de solda, bem como uma macrografia obtida através de um corte transversal ao cordão. Observa-se que com a energia empregada foi possível obter um cordão de solda com penetração completa e sem defeitos macroscópicos.

A variação de dureza e as microestruturas representativas nas diferentes regiões da junta soldada, exceto para o metal base (ver Seção 2), estão representadas na Figura 8.

(a)

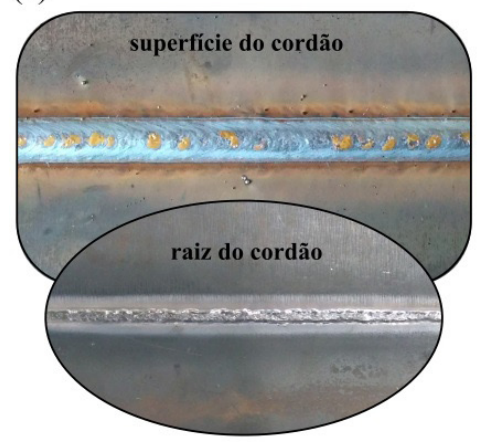

(b)

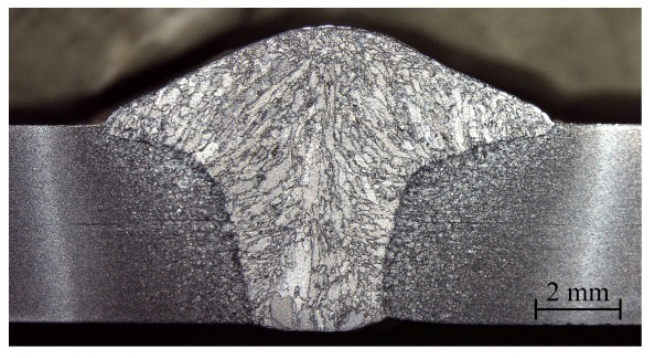

Figura 7. (a) Imagens da superfície e raiz do cordão de solda; e (b) Macrografia do cordão de solda.

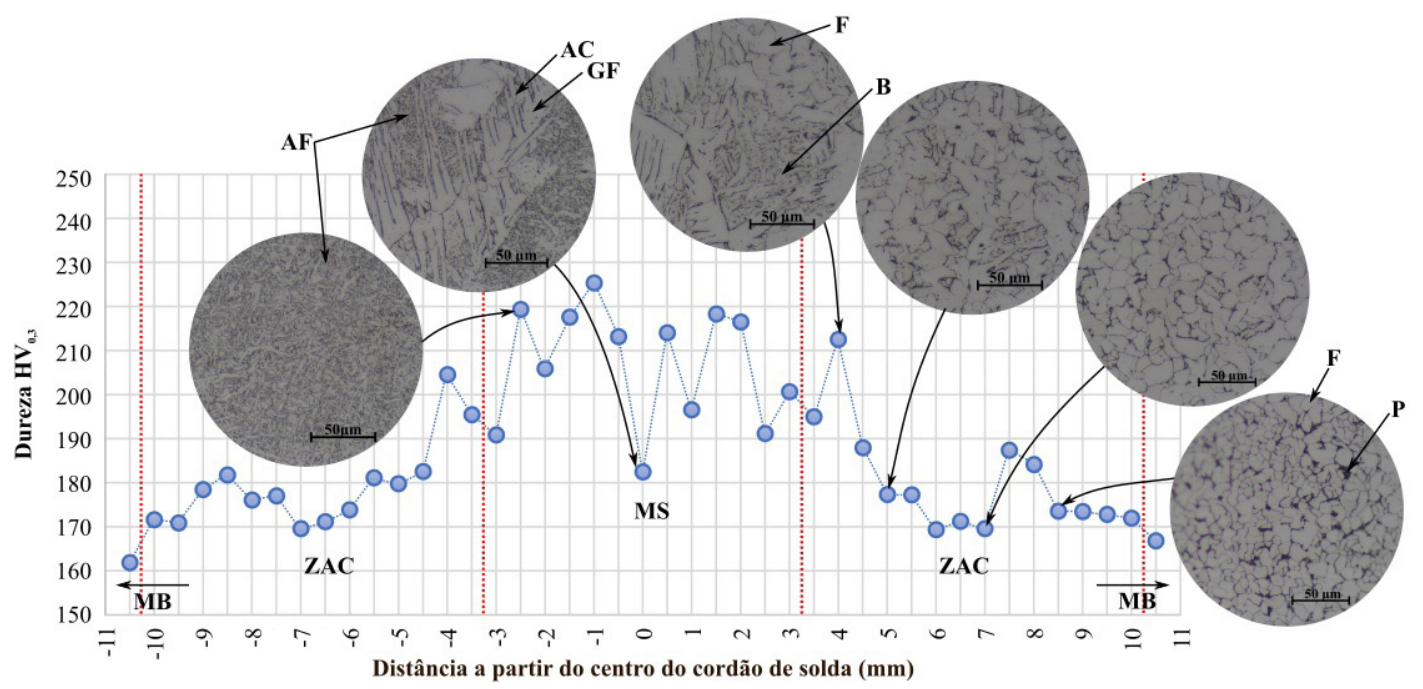

Figura 8. Perfil de microdureza e microestruturas (ataque Nital 10\%). F - ferrita; P - perlita; B - bainita; AF - ferrita acicular; GF - ferrita de contorno de grão; AC - ferrita com carbonetos alinhados; MB - metal base; ZAC - zona afeta pelo calor; MS - metal de solda. 
No metal de solda foram observados grãos colunares e equiaxiais de ferrita, os quais apresentaram uma dureza média de 207 HV. Nota-se uma variação nos valores de dureza nessa região; esta variação está associada a microestrutura nestes pontos. As regiões com maior quantidade de ferrita acicular apresentaram maior dureza, já as regiões com maior quantidade de ferrita de contorno de grão e ferrita com carbonetos alinhados apresentaram durezas menores. A dureza média na ZAC foi de 180,1 HV, a região de crescimento de grãos, na qual foram realizados os ensaios de microdesgaste por deslizamento, apresentou uma dureza de 196,4 HV. A maior dureza nesta região da ZAC deve-se a sua proximidade com relação ao metal de solda, o que faz com que ela experimente as maiores taxas de resfriamento, onde há também o crescimento dos grãos de austenita, que facilitam a formação de microestruturas mais duras como a martensita ou bainita juntamente com ferrita [5]. Com as condições de soldagem aplicadas neste estudo, e para esse aço, a microestrutura formada nesta região foi ferrita e bainita. As microestruturas observadas na ZAC e no metal de solda foram semelhantes às observadas por outros autores em metais com composição química similares [5,11,20].

\subsection{Ensaio de desgaste abrasivo roda de borracha}

No ensaio de desgaste Roda de Borracha, Figura 9, a perda de volume e a taxa de desgaste na região da junta soldada em contado com a roda de borracha foram $21,5 \%$ menores do que no MB, mostrando que a junta soldada possui uma maior resistência ao desgaste que o MB. Essa região da junta soldada era composta pelo MS e parte da ZAC de grãos grosseiros, e apresentava durezas maiores que o metal base.

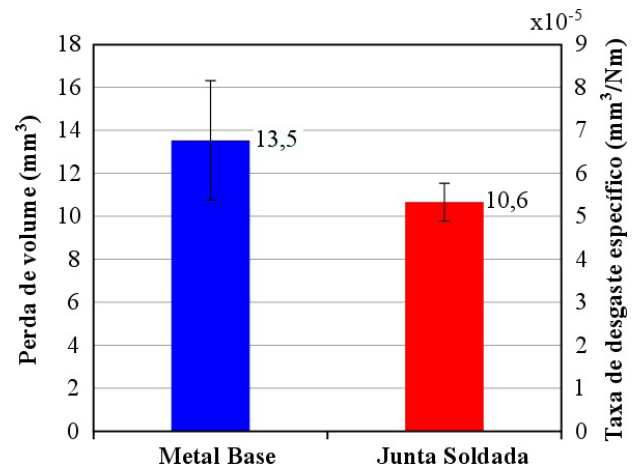

Figura 9. Resultados dos ensaios de desgaste abrasivo Roda de Borracha.

Analisando a microestrutura da superfície logo abaixo da região de desgaste, Figura 10, nota-se que no metal base a deformação plástica nesta região é maior do que na junta soldada. Nos dois casos é possível visualizar marcas de indentação de partículas (a areia utilizada no ensaio), no entanto no metal base há também uma maior região de desprendimento de material, logo acima da região de deformação plástica. Segundo Sharma et al. [21], a diferença na resistência ao desgaste de diferentes estruturas ocorre devido aos diferentes mecanismos de danos superficiais que operam em cada caso, como também aos complexos fenômenos experimentados na sub-superfície de desgaste, como a formação de trincas ou vazios, arrancamento de colônias de perlita, dissolução de carbonetos, entre outros.
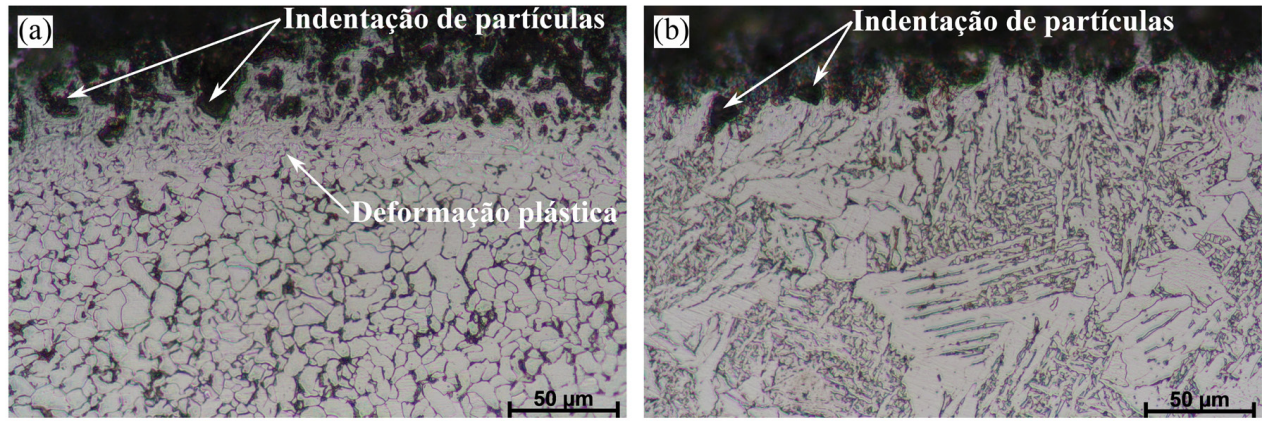

Figura 10. Metalografias transversais às trilhas geradas nos ensaios de desgaste abrasivo Roda de Borracha: (a) metal base; e (b) junta soldada. 
Nas imagens geradas no microscópio eletrônico de varredura da face superior da superfície desgastada, Figura 11, pode-se notar que houve o desprendimento de material, possivelmente pelo efeito de rolamento das partículas sobre esta superfície. Nahvi et al. [22], em um estudo sobre o movimento das partículas no ensaio de desgaste roda de borracha utilizando aços com diferentes durezas e diferentes cargas, concluiu que o movimento de rolamento das partículas é favorecido pela aplicação de baixas cargas e materiais com baixa dureza enquanto o deslizamento das partículas sobre a superfície ocorre quando da aplicação de altas cargas e com a utilização de materiais com durezas mais elevadas.
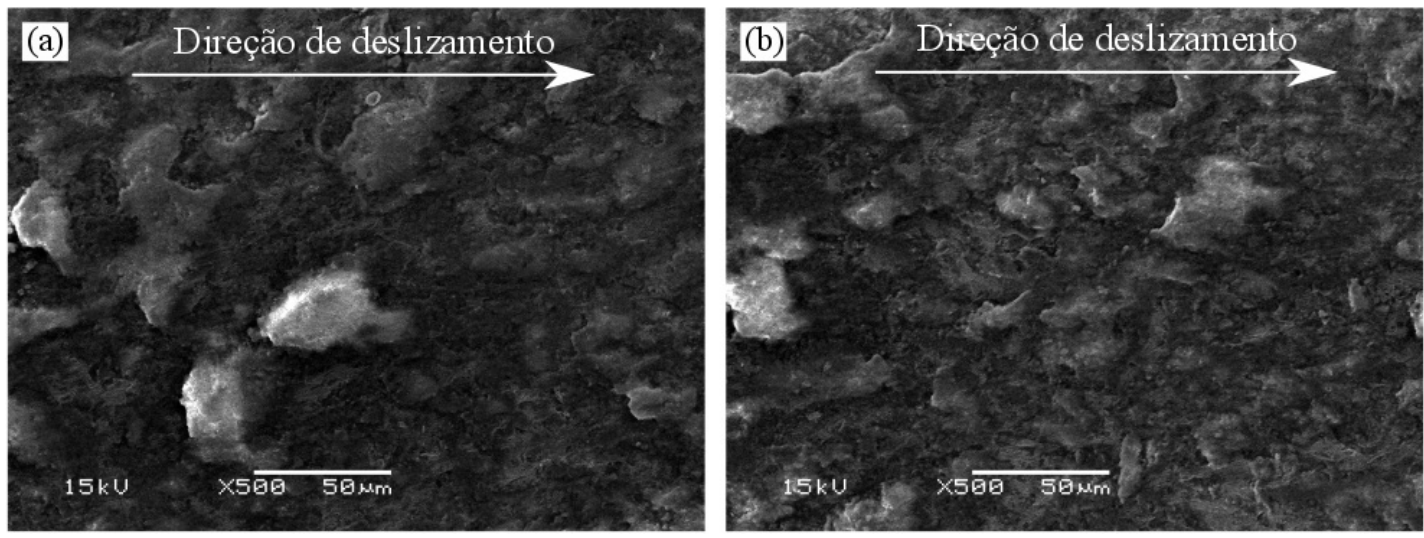

Figura 11. Imagens de MEV da face superior das trilhas geradas nos ensaios de desgaste abrasivo Roda de Borracha: (a) metal base; e (b) junta soldada.

\subsection{Ensaio de microdesgaste por deslizamento}

A Figura 12a apresenta a perda de volume na trilha e na esfera para as três regiões analisadas: MB, MS e ZAC, nesta última região a análise foi concentrada especificamente na região de grãos grosseiros (ZAC-GG), uma vez que esta região também foi abrangida pelo ensaio Roda de Borracha. A perda de volume no MS foi 8,3\% menor que a do MB, já a ZAC-GG apresentou 46,3\% menor perda de volume que o MB. Comparando o MS e a ZAC-GG, a perda de volume da ZAC-GG foi $41,42 \%$ menor que o MS. Na esfera nota-se pouca variação da perda de volume nestas regiões.
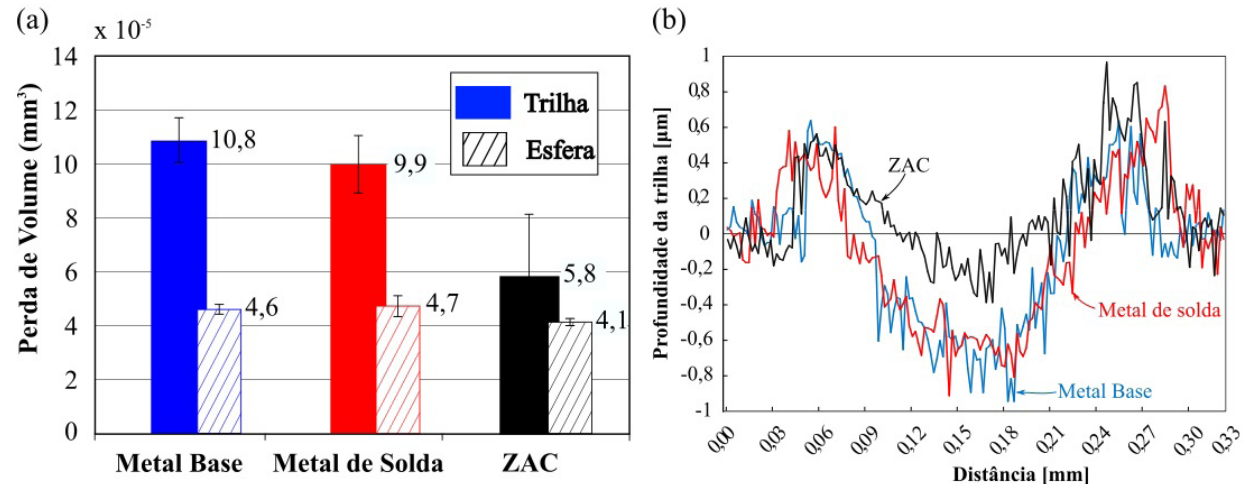

Figura 12. (a) Resultados dos ensaios de microdesgaste por deslizamento; e (b) Perfil da seção transversal as trilhas das regiões analisadas: MB, MS e ZAC-GG.

Na ZAC-GG foi registrada a maior resistência ao desgaste das três regiões analisadas, porém a dureza nesta região é menor do que no MS. Este comportamento pode estar associado a eventual geração de tensões residuais no MS e na ZAC [11,23], como também as diferenças microestruturais observadas nestas regiões. Wang et al. [24] 
Influência das Microestruturas Resultantes no Desgaste Abrasivo e por Deslizamento de um Aço Estrutural ASTM A242 Soldado pelo Processo MAG

afirmaram que as diferenças de resistência ao desgaste para várias microestruturas dependem de sua estabilidade em relação ao aquecimento por fricção, a sua resistência à deformação plástica e a resistência à iniciação e propagação de microtrincas durante o deslizamento. Xu et al. [25], em um estudo sobre aços resistentes a abrasão, concluiu que comparado com as microestruturas monofásicas (ferrita, perlita, bainita e martensita), uma microestrutura bifásica (como por exemplo, ferrita + bainita/martensita) pode oferecer maior resistência à abrasão em combinação com baixa dureza. A alta resistência a abrasão de microestruturas bifásicas pode ser atribuída à combinação da capacidade de suportar altas tensões dos constituintes mais duros e da resistência ao impacto da ferrita (fase mais macia e dúctil).

Na Figura 12b estão representados perfis transversais às trilhas de desgaste nas três regiões analisadas. $\mathrm{Na}$ ZAC-GG, a trilha apresentou menor profundidade do que nas outras regiões, refletindo a menor perda de volume, no entanto a deformação nas laterais das trilhas foi semelhante nas três regiões. Nas imagens das trilhas, Figura 13, nota-se a presença de material removido do interior da trilha nas laterais das mesmas. Na ZAC-GG este acúmulo foi menor que nas outras regiões. Como discutido anteriormente, nesta região a microestrutura formada é bifásica (ferrita + bainita), possivelmente a fase mais macia e dúctil permitiu que ocorresse deformação plástica, enquanto que a segunda fase (bainita, fase mais dura e resistente) restringiu a remoção de material do interior da trilha, aumentando a resistência ao desgaste nesta região.
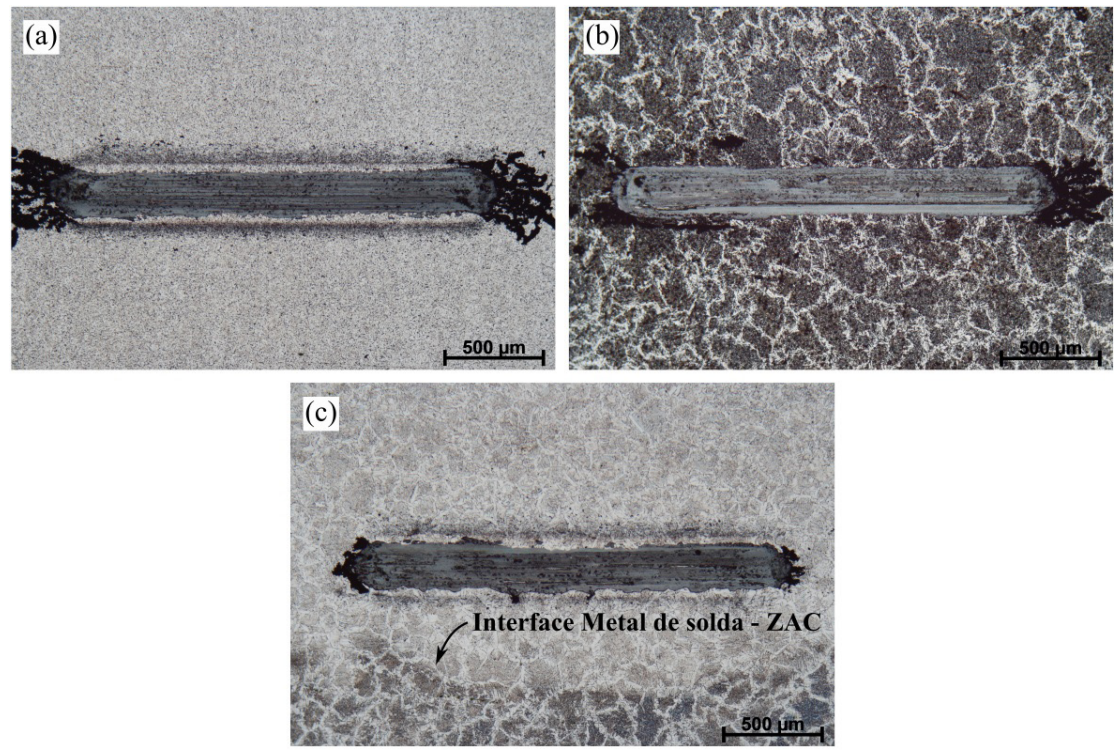

Figura 13. Imagens das trilhas nas diferentes regiões analisadas nos ensaios de microdesgaste por deslizamento: (a) MB; (b) MS; e (c) ZAC-GG. As regiões escuras na ponta das trilhas são o material removido durante o desgaste.

Analisando a microestrutura da superfície logo abaixo da região de desgaste, Figura 14, observa-se no metal base um comportamento geral muito similar ao observado no ensaio Roda de Borracha, onde houve uma maior área de deformação plástica nesta região comparada as outras duas regiões desgastadas, MS e ZAC-GG.

Na Figura 15 é possível visualizar deformação plástica, principalmente nas extremidades da trilha, uma vez que neste ponto ocorre a inversão do movimento da esfera, como também regiões onde ocorreu a remoção de material, o que pode ter ocorrido através do mecanismo de adesão.

As curvas do coeficiente de atrito cinético, obtidas com a aplicação de uma carga normal de $10 \mathrm{~N}$, estão representadas na Figura 16. Nota-se que houve um período inicial, onde o coeficiente de atrito é menor e após este entra em regime permanente. Os valores médios do coeficiente de atrito, calculados durante o regime permanente foram os seguintes: MB: 0,413 \pm 0,003, MS: 0,403 $\pm 0,023$ e ZAC-GG: 0,391 $\pm 0,015$. Estes valores estão próximos aos apresentados pela literatura em ensaios de deslizamento utilizando o par aço-alumina [26,27]. Observou-se que a região mais resistente ao desgaste, a ZAC-GG, apresentou o menor coeficiente de atrito, e o 

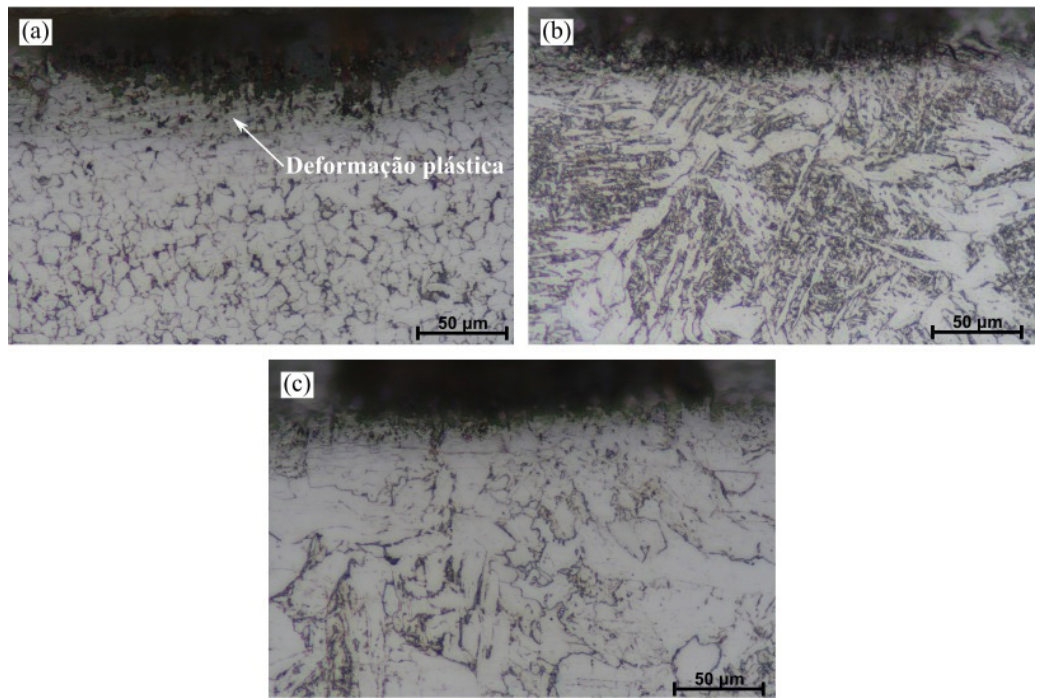

Figura 14. Metalografias transversais às trilhas nas diferentes regiões analisadas nos ensaios de microdesgaste por deslizamento: (a) MB; (b) MS; e (c) ZAC-GG.

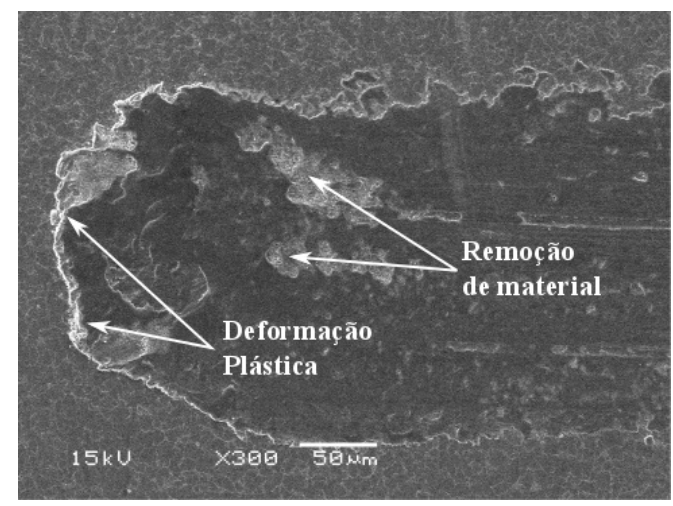

Figura 15. Imagem de MEV da face superior e extremidade de uma trilha gerada nos ensaios de microdesgaste por deslizamento no MB.

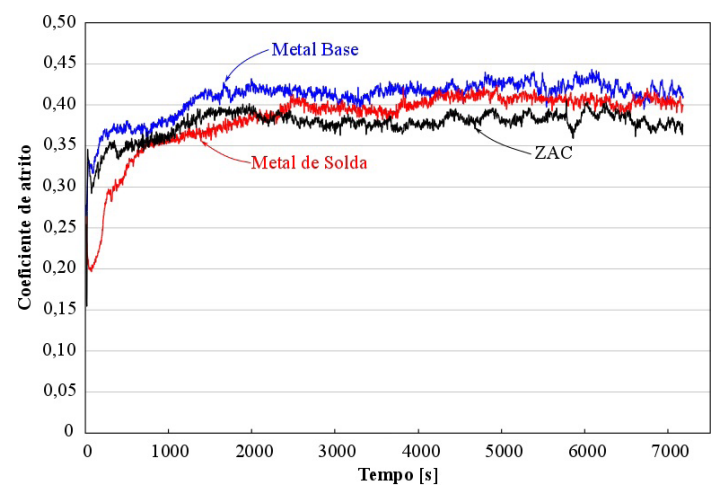

Figura 16. Coeficiente de atrito cinético em função do tempo para as diferentes regiões analisadas.

metal base, que exibiu a menor resistência ao desgaste, apresentou um coeficiente de atrito mais elevado que as demais regiões, o que neste último caso pode ser atribuído à maior deformação plástica do material, como foi mostrado nas Figuras 10 e 14. Essa deformação pode ter facilitado o mecanismo de adesão, que contribuiu para um aumento da taxa de desgaste do material, o que também foi mostrado por Buckley e Miyoshi [28]. 
Influência das Microestruturas Resultantes no Desgaste Abrasivo e por Deslizamento de um Aço Estrutural ASTM A242 Soldado pelo Processo MAG

\subsection{Comparação entre o ensaio de desgaste abrasivo roda de borracha e de microdesgaste por deslizamento}

Como citado anteriormente, o ensaio roda de borracha abrange uma área delimitada pela largura da borracha, enquanto o ensaio por deslizamento analisa cada região individualmente, por tratar-se de um ensaio em microescala. Desta forma, não serão comparadas as perdas de volume, mas somente a relação entre as resistências ao desgaste obtidas entre os diferentes ensaios empregados.

Nos dois ensaios foi observado que o metal base apresentou a menor resistência ao desgaste, muito provavelmente devido a sua microestrutura e menor dureza comparada às demais regiões analisadas, MS e ZAC-GG. Nos dois ensaios foi observada maior deformação plástica na sub-superfície de desgaste do MB, quando comparada as outras regiões ensaiadas.

\section{Conclusões}

Neste artigo foi avaliada a influência do processo de soldagem na resistência ao desgaste de uma junta soldada do aço estrutural ASTM A242. A partir dos resultados gerados observou-se que:

- Com os parâmetros utilizados no processo de soldagem foi possível obter um cordão de solda com penetração completa e sem defeitos macroscópicos;

- O metal de solda foi a região que apresentou maior dureza na junta soldada, seguido pela ZAC de grãos grosseiros e, em ambos, a dureza observada foi maior do que a do metal base;

- No ensaio de desgaste roda de borracha, o metal base apresentou 21,5\% menor resistência ao desgaste do que a junta soldada;

- No ensaio de microdesgaste por deslizamento, a resistência ao desgaste do metal base foi 8,3\% menor que do que o metal de solda e 46,3\% menor do que na ZAC-GG. Comparando o metal de solda e a ZAC-GG, a perda de volume da ZAC-GG foi 41,42\% menor que o metal de solda. Estas regiões, que exibiam microestruturas e durezas diferentes, mostraram diferença na resistência ao desgaste;

- O coeficiente de atrito apresentou uma pequena variação em relação às regiões analisadas, sendo observado seu maior valor na região que apresentou a menor resistência ao desgaste;

- A microestrutura do metal base facilitou a deformação plástica, de tal forma que em ambos ensaios realizados houve maior volume desgastado no metal base quando comparado ao MS e ZAC-GG.

\section{Agradecimentos}

Os autores agradecem a empresa ArcelorMittal S.A pelo fornecimento do material. A autora Daniela Fátima Giarollo agradece à Coordenação de Pessoal de Nível Superior (CAPES) pela bolsa de mestrado.

\section{Referências}

[1] Murata T. Weathering steel. In: Revie RW, editor. Uhlig's corrosion handbook. 3rd ed. New Jersey: John Wiley \& Sons; 2000.

[2] Morcillo M, Chico B, Díaz I, Cano H, De la Fuente D. Atmospheric corrosion data of weathering steels: a review. Corrosion Science. 2013;17:6-24. http://dx.doi.org/10.1016/j.corsci.2013.08.021.

[3] Holmberg K, Kivikytö-Reponen P, Härkisaari P, Valtonen K, Erdemir A. Global energy consumption due to friction and wear in the mining industry. Tribology International. 2017;11:116-139. http://dx.doi.org/10.1016/j.triboint.2017.05.010.

[4] Kou S. Welding metallurgy. 2nd ed. New York: John Wiley \& Sons; 2003. 461 p.

[5] Easterling K. Introduction to physical metallurgy of welding. 2nd ed. Burlington: Butterworth-Heinemann; 1992. 270 p.
[6] Lima AC, Ferraresi VA. Análise da microestrutura e da resistência ao desgaste de revestimento duro utilizado pela indústria sucroalcooleira. Soldagem e Inspeção. 2009;14(2):140-150. http://dx.doi.org/10.1590/S0104-92242009000200006.

[7] Kang AS, Singh G, Cheema GS. Improving wear resistance via hardfacing of cultivator shovel. Material today. Proceedings. 2017;4:7991-7999.

[8] Zaw Oo H, Muangjunburee P. Wear behaviour of hardfacing on $3.5 \%$ chromium cast steel by submerged arc welding. Materials Today: Proceedings. 2018;5(2):9281-9289.

[9] Singla YK, Arora N, Dwivedi DK. Dry sliding adhesive wear characteristics of Fe-based hardfacing alloys with different $\mathrm{CeO} 2$ additives: a statistical analysis. Tribology International. 2017;105:229-240. http://dx.doi.org/10.1016/j.triboint.2016.10.015. 
[10] Rojacz H, Pahr H, Baumgartner S, Varga M. High temperature abrasion resistance of differently welded structural steels. Tribology International. 2017;113:487-499. http://dx.doi. org/10.1016/j.triboint.2017.01.039.

[11] Krishnan SN, Toppo V, Basak A, Ray KK. Wear behaviour of a steel weld-joint. Wear. 2006;260(11-12):1285-1294. http:// dx.doi.org/10.1016/j.wear.2005.08.007.

[12] Pontel HF. Estudo do desgaste abrasivo e propriedades mecânicas de um aço hardox 500 soldado por MAG convencional [dissertação de mestrado]. Porto Alegre: Universidade Federal do Rio Grande do Sul; 2016.

[13] ESAB. Catálogo de consumíveis. Contagem; 2018 [acesso em 2 abr. 2018]. Disponível em: http://www.esab.com.br/br/pt/ support/documentation/upload/catalogo-consumiveis-esab. pdf

[14] Hackenhaar W, Mazzaferro JAE, Gonzalez AR, Machado IG. Influência da vazão e geometria da região de entrada sobre a eficiência térmica medida por um calorímetro de fluxo contínuo de água. Soldagem e Inspeção. 2016;21(3):269-281. http:// dx.doi.org/10.1590/0104-9224/SI2103.03.

[15] American Society for Testing and Materials. ASTM G65: standard test method for measuring abrasion using the dry sand/rubber wheel apparatus. West Conshohocken: ASTM; 2016. 14 p.

[16] Al-Rousan T, Masad E, Tutumluer E, Pan T. Evaluation of image analysis techniques for quantifying aggregate shape characteristics. Construction \& Building Materials. 2007;21(5):978-990. http:// dx.doi.org/10.1016/j.conbuildmat.2006.03.005.

[17] Archard JF. Contact and rubbing of flat surfaces. Journal of Applied Physics. 1953;24(8):981-988. http://dx.doi.org/10.1063/1.1721448.

[18] American Society for Testing and Materials. ASTM G133: standard test method for linearly reciprocating ball-on-flat sliding wear. West Conshohocken: ASTM; 2016. 9 p.

[19] De Moerlooze K, Al-Bender F, Van Brussel H. An experimental study of ball-on-flat wear on a newly developed rotational tribometer. Wear. 2011;271(7-8):1005-1016. http://dx.doi. org/10.1016/j.wear.2011.01.027.

[20] Zhen S, Duan Z, Sun D, LiY, Gao D, Li H. Study on microstructures and mechanical properties of laser-ar hybrid welded s $355 \mathrm{j} 2 \mathrm{w}+\mathrm{n}$ steel. Optics \& Laser Technology. 2014;59:11-18. http://dx.doi. org/10.1016/j.optlastec.2013.11.021.

[21] Sharma S, Sangal S, Mondal K. Influence of subsurface structure on the linear reciprocating sliding wear behavior of steels with different microstructures. Metallurgical and Materials Transactions. A, Physical Metallurgy and Materials Science. 2014;45(13):6088-6102. http://dx.doi.org/10.1007/s11661014-2555-z.

[22] Nahvi S, Shipway PH, Mccartney DG. Particle motion and modes of wear in the dry sand-rubber wheel abrasion test. Wear. 2009;267(11):2083-2091. http://dx.doi.org/10.1016/j. wear.2009.08.013.

[23] Lancaster JF. Metallurgy of welding. 6th ed. Cambridge: Woodhead Publishing; 1999. 446 p. http://dx.doi.org/10.1533/9781845694869.

[24] Wang Y, Lei T, Liu J. Tribo-metallographic behavior of high carbon steels in dry sliding: II. microstructure and wear. Wear. 1999;231(1):12-19. http://dx.doi.org/10.1016/S00431648(99)00116-7.

[25] Xu X, Xu W, Ederveen FH, Zwaag S. Design of low hardness abrasion resistant steels. Wear. 2013;301(1-2):89-93. http:// dx.doi.org/10.1016/j.wear.2013.01.002.

[26] Kumar S, Bhattacharyya A, Mondal DK, Biswas K, Maity J. Dry sliding wear behaviour of medium carbon steel against an alumina disk. Wear. 2011;270(5-6):413-421. http://dx.doi. org/10.1016/j.wear.2010.12.007.

[27] Espallargas N, Mischler S. Dry wear and tribocorrosion mechanisms of pulsed plasma nitrided Ni-Cr alloy. Wear. 2011;270(7-8):464471. http://dx.doi.org/10.1016/j.wear.2010.12.008.

[28] Buckley DH, Miyoshi K. Friction and wear of ceramics. Wear. 1984;100(1-3):333-353. http://dx.doi.org/10.1016/00431648(84)90020-6. 